\title{
Research on Safety Management of Tall Template Support System Based on BIM
}

\author{
Dongsheng $\mathrm{Yu}^{1, \mathrm{a}}$ and Jintuan Zhang ${ }^{1, \mathrm{~b}^{*}}$ \\ ${ }^{1}$ Hezhou University in Guangxi, China \\ ayudongshengbmd@163.com, b349853900@qq.com \\ ${ }^{*}$ The corresponding author
}

Keywords: BIM; Tall template support system; Safety management

\begin{abstract}
In order to improve the security and stability of tall template support system during the construction, the papers apply BIM to the safety management of tall template support system. Put forward to design method, arrange construction scheme, construction technology disclosure, dynamic progress control, establish organization of tall template support system based on BIM. So as to serve as reference for the construction management work of tall template support system in the following days.
\end{abstract}

\section{Introduction}

With construction projects develop in the direction of large span and large space gradually in our country, bring higher requirement to the template support system used as temporary structure in construction, but the template support system was not get enough attention in long time, leading to the safety accident of template support system happened frequently, stunting the sustainable development of the construction.

Building information modeling (BIM) is a hot topic in current construction, which provides industrialization, modernization and informatization to the construction technology support. The article put BIM technology into safety management of tall template support system, proposing safety management measures to template support system based on BIM.

\section{BIM Technology Survey}

Definition of BIM in BIM the National Building Information Modeling Standard, (NBIMS), contains three layers of meaning [1]:

(1) BIM is under open standard physical and functional characteristics of the construction project of digital expression.

(2) BIM is a Shared knowledge database, contains the project from planning to dismantle all information in the whole life cycle, provide reliable decision basis for all participants.

(3) Each participant can be extracted in different phases of the project, the information in the BIM model, and even modify, update, insert information, in order to realize information sharing between different parties.

BIM and Information. Building information model (BIM) is a digital model which established by $3 \mathrm{D}$ technology, could be integrating different information of the project life cycle, and creating the project entity and function as a whole [2]. Architectural components can be described in parameterization use BIM. These parameterized components include the geometry information of building components, component material specifications, cost information [3]. The phenomenon of information asymmetry and information distortion would be solved through extracting this information during construction.

Feasibility Analysis for Using BIM. Apply BIM to a project, it represents the management of information, the information will be provided by all project participants and sharing [4]. However, BIM technology is not only store information, but also own the characteristics of visualization, simulation, collaboration. When we talk about BIM, we cannot leave the BIM software, but the 
BIM technology can't simply equated with software, software is applied to implement the specific function of BIM technology. Such as we can use BIM tool software to implement artifacts associated changes, intelligent linkage, visual design, the design result is automatically generated by the model of information model, drawing, working, etc.[5]. With the application of BIM technology, collaborative work and coordination ability have received more attention, the coordinated ability in general is more integrated project implementation and management professional ability of team cooperation between the parties [6].

Tall template support system safety management can be roughly divided into three aspects: design, construction and organization management, so we can use BIM technology to provide visual design, 3D dynamic display, team working, and other functions, the safety management based on BIM technology apply to the tall template support work could be feasible.

\section{Safety Management Measures of Tall Template Support System Based on BIM}

Template support system is mainly composed by fastener type scaffolding, bowls button scaffolding, gantry scaffolding, which usually used as temporary engineering structure in construction[7]. Due to the fastener scaffold still used commonly now, the paper regard fastener scaffold as the research object yet

The social demand for large span and large space building function more than before, making the formwork supports system set up must be more higher and span more bigger, and it bring the trouble to the support system in construction. There were 7 template support system collapses among the accidents in third quarter of 2016 years, and killed 27 people. The percentage of accidents and killed people in these accidents were $33.33 \%$ and $35.53 \%$ [8].

Thus it can be seen that there are many problem in tall template support system's safety management work. So the article wills analysis the safety management of tall template support system from the following aspects.

Tall Template Support System Design Based on BIM. It could be expressing the special plan layout accurately, node details, show 3D rendering of spatial location relationship by building a BIM model, based on BIM visualization, virtual construction and fast statistical functions[9].

So we can use the visual design function to implement the visualization design of the formwork support system, making the results more intuitive design. At the same time we can get some information such as setting parameters information. As shown in the figure below, we establish the model of template scaffold by using GMJ software of Glodon. We can achieve the calculation of the supporting system as long as we set up the model. And when we change any information of the model, the calculation will be changed soon. It is turely that we can improve the design efficiency of template support system based on BIM.

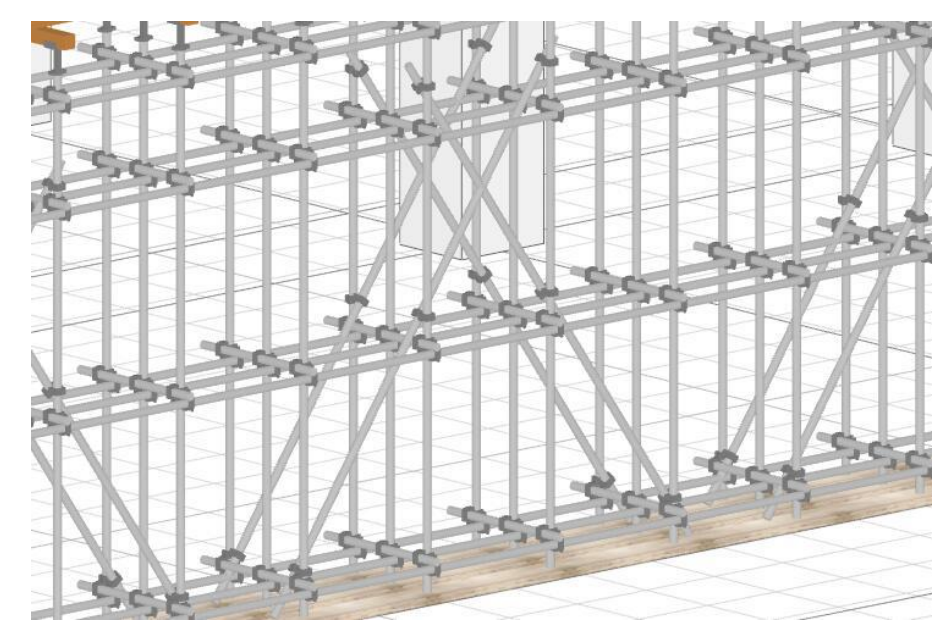

Figure 1. Three-dimensional information model of template support system 


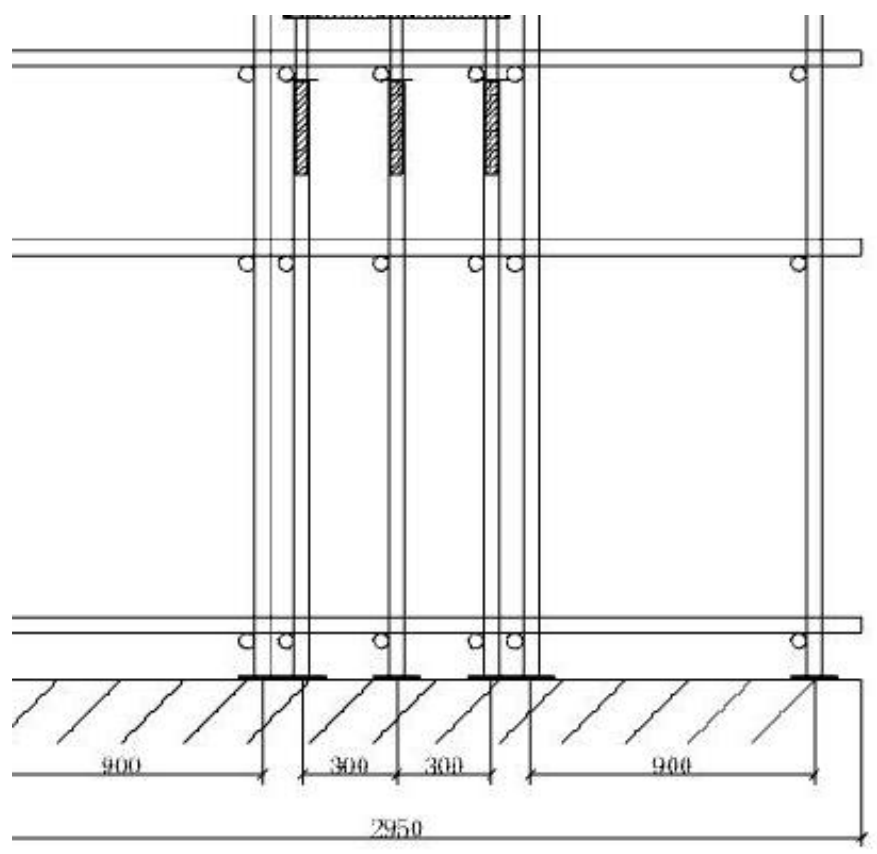

Figure 2. Template support system computing model

When we design the 3D model of template support system, we can combine with the person's experience who worked on construction square. Thus the design result can be more accurate, reduce the mistakes, and own more constructability.

Establish Construction Plan Based on BIM. When we get the template support system design result, we can extract the information about the support system from the 3D information model. Use these information we could assemble the construction directly. And we can choose a suitable plan combine BIM with the method of VE, AHP, etc. from several construction schemes. When we revise the model, the construction plan can be changed instantly. Reducing the recurring cost.

\section{Construction Technology Disclosure and Dynamic Control Based on BIM.}

Virtual construction of BIM could simulate the whole construction process, accurately certain each component's position before construction. Guarantee the fine management in construction engineering [10].

Establish the VDC of formwork support system based on BIM model, then we can use the progress of VDC to arrange construction technology disclosure, this method can enhance the recognize of formwork support system's construcion progress, and reduce the mistakes in working, avoid the emergence of the phenomenon of information asymmetry.

At the same time, we can put the model into our phone or pad, comparing this model with the support system in constructing to find out the support system in actual is lag or not. So that we can adjust the plan in time.

\section{Establish Safety Management Organization.}

To establish organization can ensure the tall template support system safety management order. Establish the organization could use the steps as follows: first, establish WBS based on the result of resolve the 3D information model, second, put the job of each elementary of WBS to every staff, third establish the linear organization structure according to the unity of target, equity of right and benefit and other principles. has unified, equivalent linear structure is established. 


\section{Conclusion}

For the frequent occurrence of safety accidents in tall template support system, the paper apply BIM technology to tall template support system safety management, put forward to tall template support system safety management in construction based on BIM. So as to give references to the safety management work of tall template support system.

\section{Acknowledgements}

Science Research and Technology Development Project of Guangxi(15122001-3-18)

Research Project of Hezhou University(2015ZC08)

Research Project of Hezhou University(2014ZD03)

\section{References}

[1] United StatesNational Building Information Modeling Standard, Version-Part 1, National Institute of Building Sciences. (2007).

[2] Y. Li, Z.Y. Liao and H.C.Yuan: Construction Technology, Vol. 44 (2014) No.supplement, pp. 522-525.(In Chinese)

[3] S.H. Jiang, H.Y. Zhang:Journal of Engineering Management, Vol. 27 (2013) No.4,pp.16-20.(In Chinese)

[4] G.P. He: BIM pandect (China Architecture \& Building Press, China 2011)

[5] J.C. Li:Time-Architecture, Vol. 2 (2013) pp. 10-15.(In Chinese)

[6] Q. Huang: Discuss BIM (China Architecture \& Building Press, China 2016)

[7] C.M. Hu, H.L. Liu, F.K. Zeng, Z.S. Ge and H.B. Yin: Industrial Construction, Vol.40 (2010) No.2, pp. 1-5.(In Chinese)

[8] http://www.mohurd.gov.cn/wjfb/201610/t20161021_229223.html

[9] Y.L. Ouyang, R.G. Liu and J. Wang: Project Management Technology, Vol. 12 (2014) No.4, pp. 47-51.(In Chinese)

[10] A.M. Jiang, S. Huang: Construction Technology, Vol. 43 (2014) No.15,pp. 86-89. (In Chinese) 